[0212-7199 (2005) 22: 2; pp 76-78] ANALES DE MEDICINA INTERNA Copyright (C) 2005 ARAN EDICIONES, S.L.

AN. MED. INTERNA (Madrid) Vol. 22, N. ${ }^{\circ} 2$, pp. 76-78, 2005

\title{
Espondilodiscitis por Candida albicans. Aportación de dos nuevos casos
}

\author{
F.L. LADO LADO, I. VILLAMIL CAJOTO, I. RODRÍGUEZ CONSTENLA, \\ E. VAN DEN EYNDE OTERO, A. PRIETO MARTÍNEZ
}

Servicio de Medicina Interna. Departamento de Medicina. Hospital Clínico Universitario de Santiago. Santiago de Compostela, A Coruña

SPONDYLODISKITIS CAUSED BY CANDIDA ALBICANS. REPORT OF TWO NEW CASES

\section{RESUMEN}

Recientemente hemos asistido a un incremento de la infección candidiásica. Los factores predisponentes son, la inmunodepresión, los catéteres, las enfermedades debilitantes, la antibioterapia prolongada, la infección por VIH y los usuarios de drogas por vía parenteral (UDVP). La espondilodiscitis debido a Candida sp.es una entidad rara. Se aportan dos casos de espondilodiscitis por Candida albicans: un varón de 29 años de edad y una mujer de 35 años. Ambos tenían antecedentes de UDVP e infección por VIH. La clínica predominante en ambos casos fue dolor, fiebre y síndrome constitucional. Presentamos las características clínicas, diagnósticas y terapéuticas de ambos casos.

PALABRAS CLAVE: Espondilodiscitis. Candida. UDVP.

\begin{abstract}
Recently, candidiasis infection is on the increase and several factors have been associated, such us immunodepression, catheters, weakening diseases, prolonged antibiotherapy, HIV infection and IDU. Spondylodiskitis due to Candida sp. is a rare entity. Two cases of spondylodiskitis due to Candida albicans were diagnosed: a 29 year-old man and a 35 year-old woman. Both were IDU's with a previous history of HIV infection. The most prominent clinical features in both cases were pain, fever and constitutional syndrome. We describe the clinical, diagnostic, and therapeutic features of both cases.
\end{abstract}

KEY WORDS: Spondylodiskitis. Candida. IDU.

Lado Lado FJ, Villamil Cajoto I, Rodríguez, Constenla I, Van den Eynde Otero E, Prieto Martínez. A. Espondilodiscitis por Candida albicans. Aportación de dos nuevos casos. An Med Interna (Madrid) 2005; 22: 76-78.

\section{INTRODUCCIÓN}

Los agentes implicados en la aparición de la espondilodiscitis son, comúnmente, el Staphylococcus aureus, la Brucella melitenses y el Mycobacterium tuberculosis. Sin embargo, la Candida sp. representa una causa excepcional de espondilodiscitis, y la mayoría de los casos son usuarios de drogas por vía parenteral (UDVP) y pacientes con antecedentes de candidemia (1-4).

Si bien, el colectivo UDVP suele presentar candidiasis diseminada con afectación cutánea, afectación ocular y afectación osteoarticular -generalmente a nivel condrocostal-, la localización vertebral constituye una rareza (5)

Presentamos dos nuevos casos de espondilodicitis por candida albicans en pacientes UDVP e infectados por el virus de la inmunodeficiencia humana (VIH).

\section{CASOS APORTADOS}

Caso 1: Varón de 29 años usuario a drogas por vía parenteral y diagnosticado de infección por VIH que seguía tratamiento antirretroviral de alta resolución. En la anamnesis, el paciente refería, desde hacía unas tres semanas, anorexia, cansancio, adelgazamiento cuantificado en 3-4 kg de peso, fiebre $\left(39^{\circ} \mathrm{C}\right)$ con escalofríos y dolor intenso localizado a nivel dorsal bajo de característica mecánicas. En la exploración física, se objetivaba mal estado general, destacando signos de venopunción periférica y dolor a la palpación y percusión de las últimas vértebras dorsales.

En los datos complementarios: los leucocitos, la fórmula leucocitaria, la hemoglobina, el hematócrito y la plaquetas no mostraron alteraciones. VSG de $50 \mathrm{~mm}$ a la primera hora. Fibrinógeno $495 \mathrm{mg} / \mathrm{dL}$ (N: 200-450) y el resto parámetros de coagulación, la bioquímica y el análisis elemental de orina fueron normales. Las

Trabajo aceptado: 23 de septiembre de 2004

Correspondencia: F. L. Lado Lado. Servicio de Medicina Interna. Hospital Clínico Universitario. 15706 Santiago de Compostela (A Coruña). e-mail: flladol@usc.es 


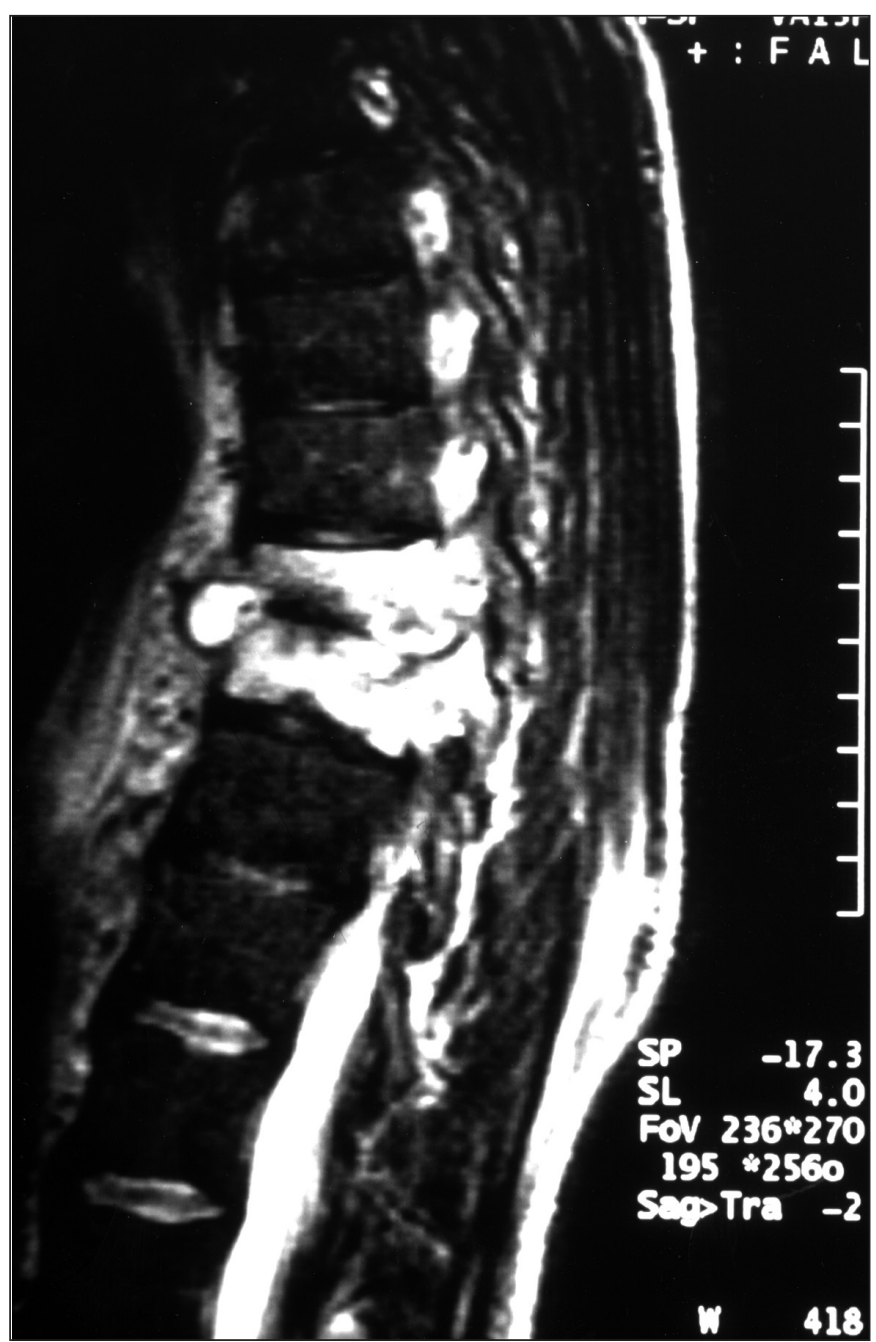

Fig. 1.- RMN de columna en la que se evidencian signos radiológicos de alteración morfológica de cuerpos vertebrales D9-D10, con desaparición del disco y presencia de masa paravertebral.

determinaciones de subpoblaciones linfocitarias CD4 fueron de $627 / \mathrm{mm}^{3}$ y la carga viral de VIH indetectable. En los estudios microbiológicos, los hemocultivos y la serología de brucella resultaron negativas. El fondo de ojo y la electromiografía no reflejaron hallazgos significativos; tampoco se constataron vegetaciones en la exploración ecocardiográfica. En la RMN de columna se evidenciaron signos radiológicos de alteración morfológica de cuerpos vertebrales D9-D10, con desaparición del disco y presencia de masa paravertebral (Fig. 1). Se realizó punción directa de la masa paravertebral y se obtuvo material purulento que fue sometido a un examen microbiológico, siendo la determinación de BAAR negativa y el cultivo positivo para Candida albicans. Se administró tratamiento secuencial con anfotericina B liposomal a dosis de 200 $\mathrm{mg} /$ día durante 15 días, seguido de fluconazol $200 \mathrm{mg} /$ día durante un total de 6 meses, evolucionando con buena respuesta clínica y radiológica con marcada mejoría de la lesión en la RMN.

Caso 2: Mujer de 35 años usuaria a drogas por vía parenteral, diagnosticada de infección por VIH y VHC que seguía tratamiento antirretroviral de alta resolución. En dos ocasiones (hacía 4 meses y 1 mes), y en relación con el consumo de droga (heroína), presentó episodios de foliculitis candidiásica y costocondritis de $2^{\circ}$ arco costal derecho respectivamente. Fue tratada con fluconazol $400 \mathrm{mg} /$ día durante 2 semanas precisando, además, de resección del cartílago costal y trayecto fistuloso. A su ingreso, en la anamnesis, la paciente explicaba un cuadro clínico, de una semana de evolución, de tos productiva con expectoración purulenta, dolor torácico izquierdo de características pleuríticas, adelgazamiento no cuantificado y dolor localizado a nivel dorsal bajo de característica mecánicas. A la exploración, no impresionaba de afectada, destacando semiología de neumonía en 1/3 inferior de hemotórax izquierdo y dolor a la palpación en apófisis espinosas de última vértebra dorsal y primeras lumbares.

En los datos complementarios: leucocitos $11.800(67 \% \mathrm{~N})$, hemoglobina 10,6, hematocrito 34, VCM 123 y plaquetas normales. VSG de $117 \mathrm{~mm}$ a la primera hora. Los parámetros bioquímicos de rutina, coagulación y el análisis elemental de orina no mostraron alteraciones. Las determinaciones de subpoblaciones linfocitarias CD4 fueron de $944 / \mathrm{mm}^{3}$ y la carga viral de VIH indetectable. En los estudios microbiológicos, los hemocultivos y la serología de brucella fueron negativas. No se constataron vegetaciones en la exploración ecocardiográfica. En la radiografía de tórax se evidenció una imagen de radioopacidad en lóbulo inferior izquierdo con derrame pleural asociado. Los estudios microbiológicos de esputo resultaron estériles con negatividad para BAAR y, en el líquido pleural (exudado de predominio mononuclear) el cultivo fue positivo para candida albicans. En la TAC de columna dorso-lumbar se hallaron signos radiológicos de espondilodiscitis con afectación tanto de cuerpos vertebrales D11, D-12 y L-1, como de espacios intervertebrales D10-D11, D11D12 y D12-L1, además de presencia de masa de tejidos blandos paravertebral y afectación intrarraquídea de localización epidural anterior. Se realizó punción directa de la masa paravertebral. Se obtuvo material purulento y en el estudio microbiológico la determinación de BAAR fue negativa y el cultivo positivo para Candida albicans. Se establecieron medidas ortésicas y tratamiento secuencial

TABLA I

CARACTERÍSTICAS DE AMBOS CASOS DE ESPONDILODISCITIS POR CANDIDA ALBICANS

\begin{tabular}{lll}
\hline Parámetros & Caso 1 & Caso 2 \\
\hline Recuento CD4 subpoblaciones linfocitarias & 627 & 944 \\
Carga viral (VIH) & Indetectable & Indetectable \\
Nivel de afectación vertebral & D9-D10 & D10-D11, D11-D12, D12-L1 \\
Otras localizaciones & No & Cutánea, pulmonar, pleural \\
Método diagnósticos & Radiológicos & Radiológicos \\
& Punción-biopsia & Punción-biopsia \\
Diagnóstico microbiológico & Candida albicans & Candida albicans \\
Tratamiento & Médico secuencial & Médico secuencial \\
& Anfotericina B liposomal (3 g) & Anfotericina B liposomal (3 g) \\
Duración & Fluconazol (200 mg/día) & Fluconazol (400 mg/día) \\
& 6 meses & 6 meses \\
\hline
\end{tabular}


con anfotericina B liposomal a dosis de $150 \mathrm{mg} /$ día durante 20 días, seguido de fluconazol $400 \mathrm{mg} /$ día durante un total de 6 meses, evolucionando con mejoría clínica y radiológica (tanto de la neumonía como del derrame pleural y de las lesiones de espondilodiscitis con afectación de cuerpos vertebrales).

En la Tabla I se exponen diversas características de ambos casos.

\section{DISCUSIÓN}

En la actualidad, hemos asistido a un incremento de la infección candidiásica siendo, entre otros, los factores implicados: inmunodepresión, catéteres, enfermedades debilitantes, antibioterapia prolongada, infección por VIH y usuarios de drogas por vía parenteral (UDVP). Todas ellas son situaciones que pueden contribuir a la implicación de Candida sp., principalmente Candida albicans y Candida tropicalis, como agente causal de la espondilodiscitis $(2-4,6)$. Los casos comentados presentaban seropositividad frente al VIH pero, muy probablemente, el virus no estuviera implicado en la aparición de la infección fúngica, ya que los resultados obtenidos en el recuento de subpoblaciones linfocitarias CD4 y en la detección de carga viral no reflejan en sí una severa inmunodeficiencia, pero si parece estar estrechamente relacionada con su hábito tóxico.

Los mecanismos por los que el drogadicto se autoinocula determinados microorganismos pasa por la contaminación de la droga, el material de inyección y/o los disolventes (7). Así, el origen de la candidiasis puede residir en la contaminación del limón necesario para disolver la heroína, en la piel, y por diseminación hematógena como bien pudo haber sucedido en nuestros casos. En uno de ellos hubo una clara candidiasis diseminada que cursó con participación concomitante cutánea, pulmonar, pleural y condrocostal. El periodo de tiempo que ocurre entre la candidemia y el diagnóstico de la espondilodisicitis puede variar entre 2 y 11 meses (8).

Clínicamente se manifiesta con dolor y fiebre aunque, en ocasiones, se acompaña de otros síntomas inespecíficos como pérdida de peso y astenia pero también ha habido casos que cursaron con síntomas neurológicos. La localización vertebral más frecuente, en más de la mitad de los casos, es la lumbar, seguida de la torácica y de la cervical. Suele ser única y afecta a uno o dos cuerpos vertebrales, no obstante se han descrito casos de afectación múltiple con dos o más focos $(2,3,7,8)$. En los casos presentados, la clínica predominante fue el dolor y la fiebre, constatándose localización dorsal en ambos; sin embargo, en uno de ellos estaba implicado más de un cuerpo vertebral con afectación de los dos últimos dorsales y el primero lumbar. En otro orden de cosas, cabe destacar que, mientras los hemocultivos pueden revelar la presencia de candidemia en hasta la mitad de los casos (4), en nuestra experiencia ambos fueron negativos.

Los hallazgos radiológicos son habitualmente expresivos y confirman la existencia de afectación vertebral pero de forma inespecífica (9). La TAC informa del grado de destrucción vertebral y de la existencia de otras lesiones locorregionales. Pese a ello, para el diagnóstico definitivo es necesaria la realización de punción/biopsia e incluso intervención quirúrgica, especialmente en aquellos casos que cursan con trastorno neurológico $(8,10)$. Los estudios histopatológicos y microbiológicos del material obtenido permiten la identificación de la lesión y del agente responsable como fue $C$. albicans en los casos referidos.

En cuanto al tratamiento, la respuesta resulta, generalmente, favorable con la administración de drogas antifúngicas, aunque no está exenta de efectos indeseables y se basa en la administración de anfotericina B sola o seguida de un azol por un período prolongado $(3,4)$. Las efectos adversos de la anfotericina B se relacionan con su nefrotoxicidad. Por el contrario, el fluconazol tiene baja nefrotoxicidad y puede administrarse oralmente, se ha mostrado eficaz como alternativa al tratamiento con anfotericina B. Otra alternativa terapéutica, manejada por nosotros y que parece ofrecer resultados óptimos, es el empleo secuencial de anfotericina B liposomal y fluconazol durante un período prolongado (11). La indicación de la intervención quirúrgica debe ser individualizada y depende de situaciones que requieran estabilización o descompresión. En nuestros casos, no fue necesario el abordaje quirúrgico con buena respuesta y tolerancia a la administración secuencial de anfotericina B liposomal y fluconazol, éste último durante un período prolongado.

A modo de conclusión, destacamos la rareza de la localización esta entidad. Así mismo que a pesar de su baja frecuencia, en pacientes UDVP con espondilodiscitis, la Candida $s p$. debe tenerse presente como agente responsable. También subrayamos que en ambos casos la infección por VIH estaba presente y no creemos que halla favorecido el desarrollo de infección por candida. Por último, queremos resaltar la buena respuesta al tratamiento médico secuencial con anfotericina $\mathrm{B}$ liposomal y fluconazol, sin necesidad de recurrir al tratamiento quirúrgico complementario.

\section{Bibliografía}

1. Silverthon KG, Guillespie WJ. Pyogenic espinal osteomyelitis: A review of 61 cases. NZ Med J 1986; 99: 62-5

2. Collet P, Biron P, Larbre JP, Llorca G, Lejeune E. Sponddylodiscites á Candida. A propos de 2 observations personnelles et de 28 observations de la littérature. Rev Med Interne 1989; 10: 413-9.

3. Hennequin C, Bourée P, Hiesse C, Dupont B, Charpentier B. Spondylodiskitis due to Candida albicans: report of two patients who were successfully treated with fluconazole and review of the literature. Clin Infect Dis 1996; 23: 176-8.

4. Miller DJ, Mejicano GC. Vertebral osteomielitis due to Candida species: case report and literature review. Clin Infect Dis 2001; 33: 523-30.

5. Dupont B, Drouhet E. Cutaneous, ocular, and osteoarticular candidiasis in heroin addicts: new clinical and therapeutic aspects in 38 patients. $\mathrm{J}$ Infect Dis 1985; 152: 577-91.

6. Parry MF, Grant B, Yukna M, Adler-Klein D, McLeod GX, Taddonio $\mathrm{R}$, Rosenstein C. Candida osteomyelitis and dikitis after spinal surgery:

an outbreak that implicates artificial nail use. Clin Infect Dis 2001; 32: 352-7.

7. Lafont A, Olivé A, Gelman M, Roca-Burniols J, Carbonell J. Candida albicans Spondylodiscitis and vertebral osteomyelitis in patients with intravenous heroin drug addiction. Report of 3 new cases. J Rheumatol 1994; 21: 953-6.

8. Gathe JC Jr, Harries RL, Garland B, Bradshaw MW, Williams TW. Candida osteomyelitis. Report of five cases and review of the literature. Am J Med 1987; 82: 927-37.

9. Pennisi AK, Davis DO, Wiesel S, Moskovitz P. CT appearance of Candida diskitis. J Comput Assist Tomogr 1985; 9: 1050-4.

10. Yu WY, Wing PC, Schweigel JF, Jetha N. Percutaneous suction aspiration for osteomyelitis: report of two cases. Spine 1991; 16: 198-202.

11. Rössel P, Sch $\Delta$ nheyder CS, Nielsen H. Fluconazole therapy in Candida albicans spondylodiscitis. Scand J Infect Dis 1998; 30: 527-30. 